\title{
A Retrospective, Iterative, Geometry-Based (RIGB) tilt-correction method for radiation observed by automatic weather stations on snow-covered surfaces: application to Greenland
}

\author{
Wenshan Wang ${ }^{1}$, Charles S. Zender ${ }^{1}$, Dirk van As ${ }^{2}$, Paul C. J. P. Smeets ${ }^{3}$, and Michiel R. van den Broeke \\ ${ }^{1}$ Department of Earth System Science, University of California, Irvine, California, USA \\ ${ }^{2}$ Geological Survey of Denmark and Greenland (GEUS), Copenhagen, Denmark \\ ${ }^{3}$ Institute for Marine and Atmospheric Research, Utrecht University (UU/IMAU), Utrecht, the Netherlands
}

Correspondence to: Wenshan Wang (wenshanw@uci.edu)

Received: 28 September 2015 - Published in The Cryosphere Discuss.: 3 November 2015

Revised: 11 February 2016 - Accepted: 11 March 2016 - Published: 24 March 2016

\begin{abstract}
Surface melt and mass loss of the Greenland Ice Sheet may play crucial roles in global climate change due to their positive feedbacks and large fresh-water storage. With few other regular meteorological observations available in this extreme environment, measurements from automatic weather stations (AWS) are the primary data source for studying surface energy budgets, and for validating satellite observations and model simulations. Station tilt, due to irregular surface melt, compaction and glacier dynamics, causes considerable biases in the AWS shortwave radiation measurements. In this study, we identify tilt-induced biases in the climatology of surface shortwave radiative flux and albedo, and retrospectively correct these by iterative application of solar geometric principles. We found, over all the AWS from the Greenland Climate Network (GC-Net), the Kangerlussuaq transect (K-transect) and the Programme for Monitoring of the Greenland Ice Sheet (PROMICE) networks, insolation on fewer than $40 \%$ of clear days peaks within $\pm 0.5 \mathrm{~h}$ of solar noon time, with the largest shift exceeding $3 \mathrm{~h}$ due to tilt. Hourly absolute biases in the magnitude of surface insolation can reach up to $200 \mathrm{~W} \mathrm{~m}^{-2}$, with respect to the well-understood clear-day insolation. We estimate the tilt angles and their directions based on the solar geometric relationship between the simulated insolation at a horizontal surface and the observed insolation by these tilted AWS under clear-sky conditions. Our adjustment reduces the root mean square error (RMSE) against references from both satellite observation and reanalysis by $16 \mathrm{~W} \mathrm{~m}^{-2}(24 \%)$, and raises the correlation coefficients with them to above 0.95. Aver-
\end{abstract}

aged over the whole Greenland Ice Sheet in the melt season, the adjustment in insolation to compensate station tilt is $\sim 11 \mathrm{~W} \mathrm{~m}^{-2}$, enough to melt $0.24 \mathrm{~m}$ of snow water equivalent. The adjusted diurnal cycles of albedo are smoother, with consistent semi-smiling patterns. The seasonal cycles and inter-annual variabilities of albedo agree better with previous studies. This tilt-corrected shortwave radiation data set derived using the Retrospective, Iterative, Geometry-Based (RIGB) method provide more accurate observations and validations for surface energy budgets studies on the Greenland Ice Sheet, including albedo variations, surface melt simulations and cloud radiative forcing estimates.

\section{Introduction}

The Greenland Ice Sheet has experienced dramatic mass loss and frequent massive melt events in the past 30 years (Nghiem et al., 2012; Tedesco et al., 2013; Velicogna and Wahr, 2013). At least half of the mass loss can be attributed to surface mass balance (van den Broeke et al., 2009; Enderlin et al., 2014; Andersen et al., 2015), which is in turn controlled by solar radiation (van den Broeke et al., 2011). Therefore, reliable measurements of surface radiative flux are essential for climate change studies in this sensitive area (Pithan and Mauritsen, 2014). In this study, we correct the station tilt problem to produce more consistent shortwave radiation (thereafter, SW) measured by the automatic weather stations (AWS). 
In the highly cloudy arctic area (Vavrus et al., 2008), studies of surface energy budgets and mass loss rely on the in situ AWS measurements of surface radiative flux, since satellites cannot see through thick clouds, and have a large uncertainty at high solar zenith angles (Wang and Zender, 2010b; Schaaf et al., 2011). Stroeve et al. (2013) evaluated cloud-free albedo retrievals from the MODerate resolution Imaging Spectroradiometer (MODIS) Terra and Aqua combined 16-day albedo product (MCD43) against in situ measurements by AWS in Greenland. They found a negative trend in albedo during summer from 2000 to 2012, with a large negative anomaly in July 2012 (0.060 lower than the average of July 2000-2009: 0.627). Wang and Zender (2010a) adjusted MODIS MCD43 albedo retrievals over snow-covered regions in Greenland to remove the low bias at large solar zenith angles, based on snow optical properties and AWS radiation measurements. The resulting adjustments in absorbed solar radiation are as large as 8.0 and $10.8 \%$ for the black-sky and white-sky albedo, respectively. Nevertheless, only AWS observe the allsky albedo. van den Broeke et al. (2011) calculated the surface energy balance (SEB) and melt rate in the ablation zone of west Greenland using a SEB model driven by hourly AWS measurements. They found that the seasonal cycle and interannual variability of melt are mainly controlled by absorption of SW, except in the lower ablation zone where the turbulent fluxes of sensible and latent heat dominate. The AWS measurements are also used in various other applications, such as to estimate cloud radiative effects on surface albedo (Kuipers Munneke et al., 2011), and to validate regional climate model simulations (Fettweis, 2007; Box et al., 2012; van As et al., 2014).

These radiative fluxes measured by unattended stations may contain considerable biases (Stroeve et al., 2001; van den Broeke et al., 2004). In the assessment of AWS in Antarctica, van den Broeke et al. (2004) summarized the typical problems of SW measurements, including icing and riming of the sensor dome, cosine response error at large solar zenith angles, and sensor tilt. Other possible problems include the shadowing of the station tower or nearby high structures, and random micro-scale environmental noise (Stroeve et al., 2005). An ice coating over the sensor dome can shield part of the incoming solar radiation, causing an underestimate of net SW. Shadows on the sensor can also lead to an underestimate. On the other hand, riming on the sensor dome can increase the incoming solar radiation, especially at large solar zenith angles, due to the enhanced multiple scattering of the solar radiation, causing an overestimate of net SW. However, in the high and dry interior of ice sheets, icing and riming are not major problems due to the small thermal mass of the pyranometers (Stroeve et al., 2001). Moreover, the unlikely high/low values induced by the icing, riming and shadowing can be removed by detecting the sudden change of albedo since the down-looking sensors are generally less sensitive to these problems. The cosine response error at large solar zenith angles is intrinsic, and variable with instrument types and manufacturers, some of which we characterize in the following. Using an intermediate resolution spectrophotometer, Grenfell et al. (1994) found the departures of measurements from an ideal cosine law were less than $15 \%$ at solar zenith angles less then $72^{\circ}$. Using a Brewer spectroradiometer in UV band, Bais et al. (1998) reported a cosine error range from 2 to $7 \%$. One of the AWS projects in Greenland, Greenland Climate Network, employs LI-COR 200SZ pyranometers. Stroeve et al. (2001) observed deviations of this pyranometer from highly accurate instruments in excess of $5 \%$ at solar zenith angles larger than $75^{\circ}$. van den Broeke et al. (2004) obtained negative net shortwave radiation at high solar zenith angles using Kipp \& Zonen CM3 pyranometers, equipped by the other two Greenland AWS projects, K-transect project and the Programme for Monitoring of the Greenland Ice Sheet networks. According to the manufacture report, the typical percentage deviation of Kipp \& Zonen CM3 from ideal cosine behavior is $\sim 2 \%$ at solar zenith angle of $80^{\circ}$, with a maximum of $\sim 8 \%$, which is on the same magnitude of that of LI-COR 200SZ (Kipp \& Zonen, 2004). The newer version of LI-COR pyranometer, LI-200R, claims a typical cosine error of less than $5 \%$ up to solar zenith angle of $82^{\circ}$ (Biggs, 2015). None of the cosine errors reported in the above proceedings exceed the mean tilt-induced biases as we document below.

The primary source of the bias in the SW is the instrument leveling (i.e., sensor tilt) (van den Broeke et al., 2004; van As, 2011; Stroeve et al., 2013). Different snow melt and compaction as well as glacier movement (A. P. Ahlstrøm, personal communication, 2015) around the station towers and/or cable anchors can cause the station to drift over time. The tilted sensors will result in either underestimates or overestimates of radiation measurements, depending on the combination of the tilt angle and tilt direction. SW is highly sensitive to sensor tilt. Theoretically, a tilt angle of $1^{\circ}$ towards $40^{\circ} \mathrm{N}$ will induce a $\sim 20 \mathrm{~W} \mathrm{~m}^{-2}$ bias in net $\mathrm{SW}$ (van den Broeke et al., 2004). Using a radiative transfer model, Bogren et al. (2015) estimated the albedo error introduced by a station tilt of $5^{\circ}$ to be $\sim 13 \%$. Moreover, the diurnal phase of radiation will be shifted, suggesting that sub-daily variabilities will be inaccurate without correcting the tilt problem. Both van den Broeke et al. (2004) and Stroeve et al. (2013) used a 24-hour running average as a workaround. van den Broeke et al. (2004) further calculated net SW by multiplying the 24-hour running average albedo with the upwelling radiation, which is less susceptible to station tilt. These workarounds provide more stable estimates of radiation and albedo. However, the only way to obtain the accurate radiation and albedo at any time scales is to correct the tilt problem. The PROMICE AWS are equipped with inclinometers, measuring the north-south and east-west tilt angles. The station rotation is obtained every 1-2 years by re-visiting the station. Insolation observed by tilted AWS can then be adjusted using this information (van As, 2011). However, in spite of the effort to re-position the stations during each visit, 
the frequent station rotation, occurring together with station tilt, changes the orientation of these inclinometers, making the measured tilt angles questionable. Moreover, the tilt problem remains at half of the AWS in Greenland with no inclinometers at all.

For longwave radiation, the most important bias source is the window heating offset (van den Broeke et al., 2004), which occurs when the silicon window is warmer than the sensor housing, caused by an excess of solar radiation absorption. Although this problem cannot be removed without knowing the window temperature, the overall effect on net longwave radiation is less than $5 \mathrm{~W} \mathrm{~m}^{-2}$ (van den Broeke et al., 2004), which is quite small relative to the shortwave bias caused by tilt discussed here.

To ameliorate tilt biases in SW measured by AWS, we introduce a new method - the Retrospective, Iterative, Geometry-Based (RIGB) tilt-correction method - that depends only on solar geometry, and no additional instrumentation. Sections 2 and 3 describe the data sets we use, and RIGB method to estimate tilt angle and tilt angle direction and to adjust SW. In Sect. 4, we evaluate our adjusted insolation against satellite observations and reanalysis at all stations, and against data from PROMICE stations, which were adjusted by the inclinometer-measured tilt angles. To what degree station tilt affects the diurnal phase and magnitude of insolation are also revealed in this section. In Sect. 5, we present the observed diurnal variability of albedo over Greenland for the first time, and show the improvement of the monthly and annual climatology using the adjusted SW. In Sect. 6, we explore the dominant factors for station tilt, and discuss the possible limitations and uncertainties of RIGB method, followed by our conclusions.

\section{Data}

AWS used in this study are from three networks: Greenland Climate Network (GC-Net), the Kangerlussuaq transect (Ktransect) and the Programme for Monitoring of the Greenland Ice Sheet (PROMICE). The first GC-Net station was set up in 1995. By 2014, there were a total of 17 long-term AWS in GC-Net, spreading in both ablation and accumulation zones (Steffen et al., 1996). Three AWS at the K-transect were initiated in 2003 (van den Broeke et al., 2011), with one more station added in 2010. Since 2007, PROMICE set up 22 AWS in succession, arranged mostly in pairs with one station in the upper ablation zone near the equilibrium line and the other at a lower elevation well into the ablation zone (van As and Fausto, 2011).

In this study, we correct the sensor tilt problem in surface SW data observed by AWS from all three aforementioned data sets during melt seasons (i.e., May-August) from 2008 to 2013, when data at most of the stations are available. Stations with more than 2 years of missing data are excluded from consideration, including Crawford Point1,

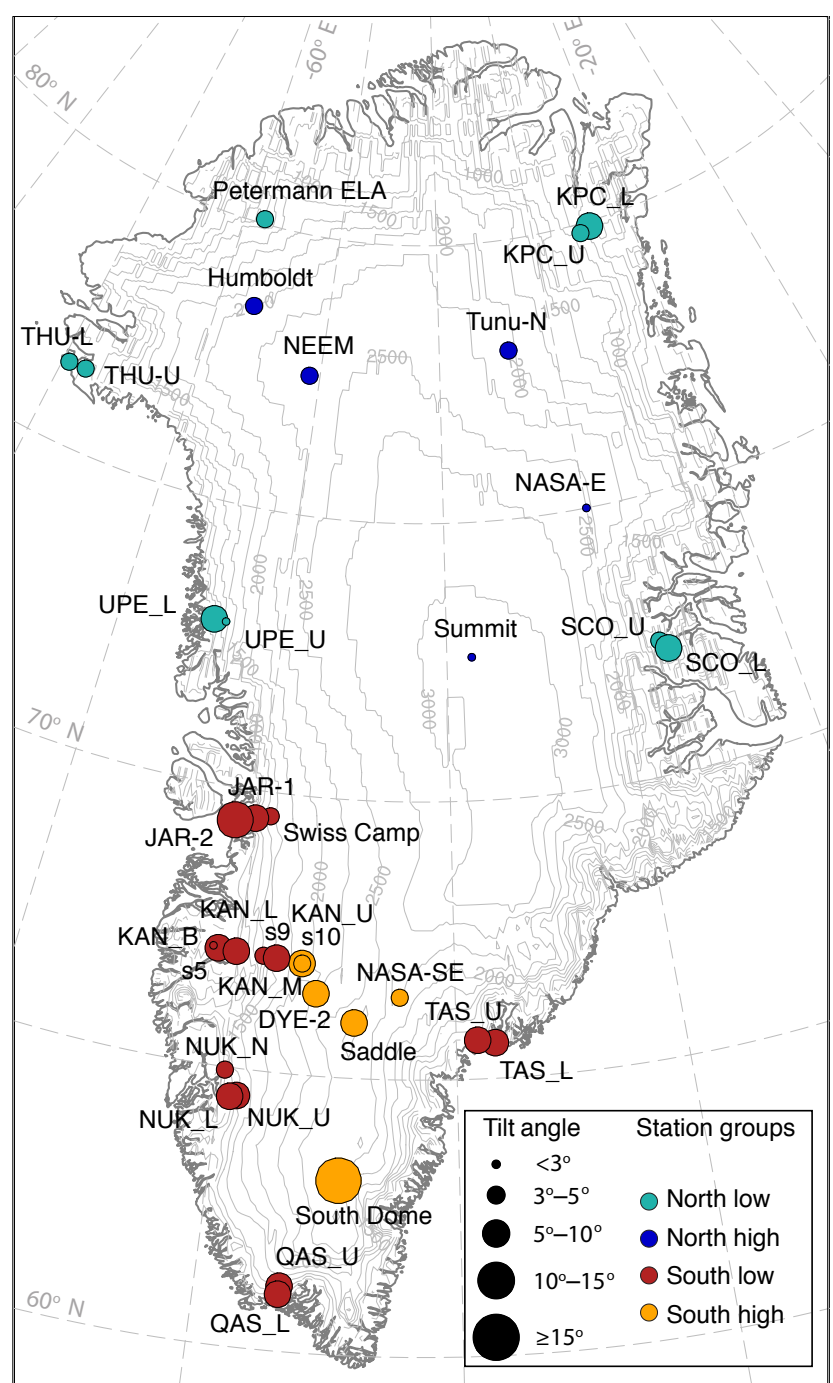

Figure 1. The automatic weather stations used in this study and their average tilt angles $(\beta)$. Stations are separated into four groups based on their latitudes and altitudes.

GITS, NASA-U and Petermann Gl. from GC-Net, s6 from K-transect, and MIT, QAS_A and TAS_A from PROMICE. The remaining number of stations is 35, of which 13 stations are from GC-Net, 3 from K-transect and 19 from PROMICE (Fig. 1). The radiative flux from these data sets is hourly average. We synchronize all three data sets to account the fact that the time stamp of GC-Net and K-transect is half an hour after the interval mid-point (i.e., data stamped as 8 a.m. represent the average from 7 to 8 a.m.); the one of PROMICE is half an hour before the interval mid-point (i.e., data stamped as 8 am represent the average from 8 to 9 a.m.). PROMICE also provides adjusted $\mathrm{SW}$ by measured tilt angles at their stations, which can be used as a reference for our method. However, this PROMICE product has not been corrected for the inclinometer orientation shift yet. 
We also use insolation from the Clouds and the Earth's Radiant Energy System (CERES) (CERES Science Team, 2015) and the Modern-Era Retrospective Analysis for Research and Applications (MERRA) (Rienecker et al., 2011) as references to evaluate RIGB adjustments. CERES instruments are now aboard three satellites, including Terra, Aqua and the Suomi National Polar-orbiting Partnership (SNPP) observatory. They measure both solar-reflected and Earth-emitted radiation from TOA, and derives solar radiative fluxes at Earth surface. The insolation we use is Synoptic Radiative Fluxes and Clouds (SYN) Edition-3A Level-3 data, the spatial and temporal resolution of which are $1^{\circ}$ and $3 \mathrm{~h}$, respectively. MERRA is the new generation of reanalysis, which uses the Data Assimilation System component of the Goddard Earth Observing System. It provides near-realtime hourly climate analysis with $1 / 2^{\circ}$ in latitude and $2 / 3^{\circ}$ in longitude.

\section{Methodology}

Based on the geometric relationship between the tilted insolation observations and simulations on a horizontal surface on clear days, we deduce tilt angles and directions, and then use them to correct the tilt-induced biases on the neighboring cloudy days.

\subsection{Surface radiative flux simulation}

We use a column radiation model (CRM), the stand-alone version of the radiation model in Community Atmosphere Model 3 (CAM3) updated from Zender (1999), to simulate surface radiative flux on clear days based on atmospheric profiles and surface conditions. Here we use atmospheric temperature profiles and humidity profiles, and surface conditions (except surface albedo) from the Atmospheric Infrared Sounder (AIRS) (AIRS Science Team/Joao Texeira, 2013). Its infrared and micro-wave (IR/MW) sounding instruments retrieve reliable profiles even near the surface (Susskind et al., 2003). Atmospheric constituents with little variability, such as $\mathrm{O}_{3}$ and AOD are set to values from a subArctic standard atmosphere (Table 1).

\subsection{Radiation on a tilted surface}

SW on a tilted surface comprises of three parts: direct radiation or beam radiation $\left(I_{\mathrm{b}, \mathrm{t}}\right)$, diffuse radiation $\left(I_{\mathrm{d}, \mathrm{t}}\right)$ and reflected radiation from a nearby horizontal surface $\left(I_{\mathrm{r}, \mathrm{t}}\right)$. These three parts can be calculated separately from tilt angle $(\beta)$ and tilt direction $\left(a_{\mathrm{w}}\right)$, time and place, and SW on the horizontal surface $\left(I_{\mathrm{h}}\right)$, assuming isotropic reflection at the surface (Goswami et al., 2000). First, the direct radiation $\left(I_{\mathrm{b}, \mathrm{t}}\right)$ is calculated from the direct part of SW on the horizontal surface $\left(I_{\mathrm{b}, \mathrm{h}}\right)$ and the solar zenith angle observed on the tilted surface $(i)$, as below:
Table 1. CRM Parameters.

\begin{tabular}{lcc}
\hline Parameter & Unit & Value \\
\hline Number of vertical levels & Layer & 100 \\
\hline Ozone column mass path & $\mathrm{DU}$ & 348.64 \\
\hline \multicolumn{3}{l}{ Aerosol visible extinction optical depth } \\
in north & - & 0.12 \\
in south & - & 0.14 \\
\hline Solar constant & $\mathrm{W} \mathrm{m}^{-2}$ & 1367.0 \\
\hline
\end{tabular}

$I_{\mathrm{b}, \mathrm{t}}=I_{\mathrm{b}, \mathrm{h}} \cdot \cos i$.

$I_{\mathrm{b}, \mathrm{h}}$ is known from the true solar zenith angle $(z)$ and the diffuse ratio $(C)$ :

$I_{\mathrm{b}, \mathrm{h}}=\frac{I_{\mathrm{h}}}{\cos z+C}$.

$\cos i$ follows the geometric relationship with the true solar zenith angle $(z)$, solar azimuth angle $\left(a_{\mathrm{s}}\right)$, tilt angle $(\beta)$ and tilt direction $\left(a_{\mathrm{w}}\right)$ :

$\cos i=\sin z \cdot \cos \left(a_{\mathrm{s}}-a_{\mathrm{w}}\right) \cdot \sin \beta+\cos z \cdot \cos \beta$.

We calculate solar declination used to estimate solar zenith angle $(z)$ and azimuth angle $\left(a_{\mathrm{s}}\right)$ using algorithm from Reda and Andreas (2004).

The diffuse radiation on a tilted surface $\left(I_{\mathrm{d}, \mathrm{t}}\right)$ can be calculated by multiplying diffuse radiation on a horizontal surface $\left(C \cdot I_{\mathrm{b}, \mathrm{h}}\right)$ by the view factor between the sky and the tilted surface, as below (assuming isotropic diffuse radiation):

$I_{\mathrm{d}, \mathrm{t}}=C \cdot I_{\mathrm{b}, \mathrm{h}} \cdot(1+\cos \beta) / 2$.

Part of the upwelling radiation from a nearby horizontal surface can be intercepted by the tilted surface. This reflected radiation on the tilted surface $\left(I_{\mathrm{r}, \mathrm{t}}\right)$ can be obtained by multiplying upwelling radiation from the horizontal surface $\left(\rho \cdot I_{\mathrm{h}}\right)$ by the view factor between the horizontal surface and the tilted surface (assuming isotropic reflected radiation):

$I_{\mathrm{r}, \mathrm{t}}=\rho \cdot I_{h} \cdot(1-\cos \beta) / 2$,

where $\rho$ is an approximation of surface albedo. A value of 0.8 is used here for snow covered ground as suggested by Goswami et al. (2000).

The relation between SW measured by the tilted sensor $\left(I_{\mathrm{t}}\right)$ and $\mathrm{SW}$ on the horizontal surface simulated by $\operatorname{CRM}\left(I_{\mathrm{h}}\right)$ can be summarized as follows:

$$
\begin{aligned}
& I_{\mathrm{t}}=\frac{I_{\mathrm{h}}}{\cos z+C} \\
& \cdot[\cos i+C \cdot(1+\cos \beta) / 2+\rho \cdot(\cos z+C)(1-\cos \beta) / 2],
\end{aligned}
$$

where $C$ is 0.25 for insolation on clear days. The relatively larger value of $C$ used here includes the effects of undetected clouds (Harrison et al., 2008). 


\subsection{Estimate of tilt angle and direction}

The SW provided by the three data sets used in this study could include all the AWS measuring problems of icing, riming, shadowing, cosine response error and sensor tilt. AWS from GC-Net use the LI-COR 200SZ pyranometer, which has a better resistance to rime formation than the standard thermopile pyranometers (Stroeve et al., 2005), due to its small thermal mass. van den Broeke et al. (2004) found the Kipp \& Zonen CM3 pyranometer, used by AWS from Ktransect and PROMICE, less susceptible to riming, since it only has a single dome (rather than double domes), which can be heated up by solar radiation together with the black sensor plate to prevent rime formation. Furthermore, using only clear days with perfect cosine curves to estimate tilt angle and tilt direction helps remove the effects of icing, riming and shadowing. Although the numerical solutions of tilt angle and tilt direction are most sensitive to insolation at solar noon, in order to further limit effect of cosine response error, we only use data at solar zenith angles smaller than $75^{\circ}$, when the cosine response error is typically less than $5 \%$ (Kipp \& Zonen, 2004; Biggs, 2015; Stroeve et al., 2001). We assume, therefore, the residual bias is mainly caused by sensor tilt, with an uncertainty in device measurement and random environmental noise. The best tilt angle-tilt direction pair, $\left(\beta, a_{\mathrm{w}}\right)$, is chosen as the pair which produces the surface insolation with the correct shift in phase $( \pm 0.5 \mathrm{~h})$ and the smallest absolute error in magnitude compared with CRM simulations.

\subsection{Data adjustment}

The best tilt angle and tilt direction pair estimated using insolation on all the clear days in 1 month is used to adjust radiation of that whole month. However, there are cases in which tilt angle changes several degrees in a month. If the standard deviation of RIGB adjustments on different clear days using this one pair of tilt angle and tilt direction is larger than $5 \mathrm{~W} \mathrm{~m}^{-2}$, this month will be divided into shorter time periods and processed separately. To adjust insolation on both clear and cloudy days (i.e., calculate radiation on the horizontal surface $I_{\mathrm{h}}$ from that on the tilted surface $I_{\mathrm{t}}$ ), Eq. 6 shown previously is used with the diffuse ratio $(C)$ calculated by the cloud fraction (CF) from CERES (van As, 2011) as follows:

$C=\frac{0.25+\mathrm{CF}}{1-\mathrm{CF}}$

Since the improvements in the shortwave upwelling radiation are negligible for the tilt angle range estimated in this study, no tilt correction is performed on it. Although only insolation at solar zenith angles less than $75^{\circ}$ is used to estimate station tilt, SW data at all solar zenith angles are adjusted, with physically impossible (i.e., insolation at surface larger than at TOA; or albedo larger than 0.99) and suspicious data (i.e., a sudden change in albedo) excluded. Missing data points with

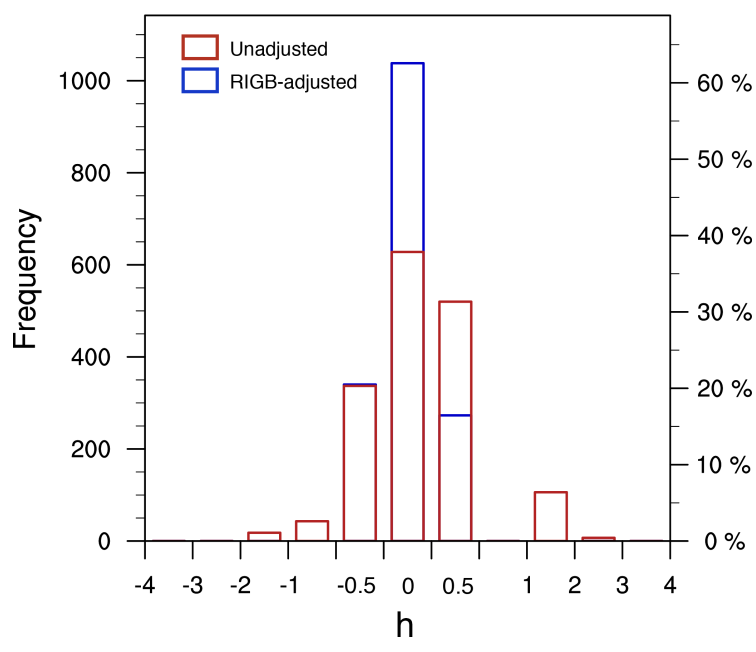

Figure 2. Shifts of maximum insolation time to solar noon in unadjusted data and RIGB adjustment. The bins of solar noon time are non-linear with a minimum of $0.5 \mathrm{~h}$.

both adjoining sides of data available are filled with linear interpolation.

\section{Validation}

Station tilt affects both the phase and magnitude of the diurnal variability of surface radiative flux. The phase shift can be discerned by comparing the time of observed insolation maximum with solar noon time under clear-sky conditions. The solar noon time at one station is known from its longitude and the date (Goswami et al., 2000; Reda and Andreas, 2004). There is a frequent shift of maximum insolation time against solar noon in the unadjusted AWS measurements at most stations (Fig. 2). On fewer than $40 \%$ of all clear days, insolation peaks within $\pm 0.5 \mathrm{~h}$ of solar noon. Some of the shifts are larger than $3 \mathrm{~h}$. On the other hand, over $60 \%$ of the RIGB-adjusted insolation peaks at solar noon. The maximum shift is $\pm 0.5 \mathrm{~h}$.

The improvements in AWS insolation are further evaluated by comparing unadjusted AWS data with RIGB-adjusted data and with the PROMICE adjustment against the CERES (CERES Science Team, 2015) and MERRA retrievals (Rienecker et al., 2011). The AWS from PROMICE are equipped with inclinometers that record the station tilt angles. The tiltcorrected data are provided whenever inclinometers worked, with no correction on the inclinometer orientation yet. We compare AWS observations with data in the nearest CERES and MERRA grid. Comparisons are only conducted between 6 a.m. and 6 p.m. at local solar time because the extrapolation of data in the early mornings and late nights - when most of the data are removed due to icing and low sensitivity problems - is problematic.

RIGB adjustment better agrees with both CERES and MERRA, relative to the unadjusted data and PROMICE ad- 

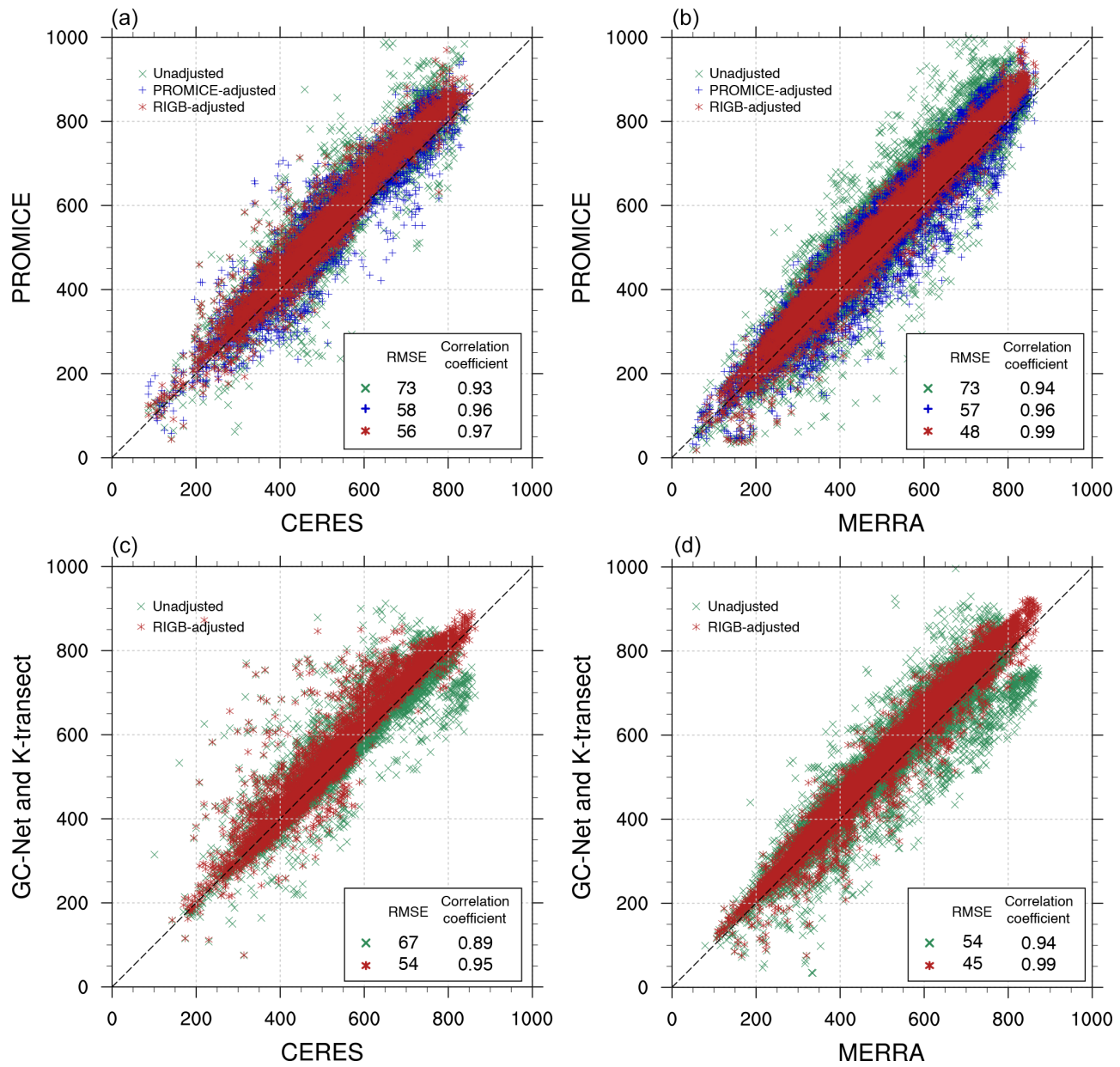

Figure 3. Correlation of insolation $\left(\mathrm{W} \mathrm{m}^{-2}\right.$ ) on clear days between (a) PROMICE with CERES; (b) PROMICE with MERRA; (c) GC-Net and K-transect with CERES; (d) GC-Net and K-transect with MERRA.

justment (Fig. 3). At PROMICE stations, the RIGB root mean square errors (RMSE) against CERES and MERRA are $\sim 20 \mathrm{~W} \mathrm{~m}^{-2}$ smaller than the RMSE of the unadjusted data, and are also smaller than the RMSE of the PROMICE adjustment (Fig. 3a, b). Correlations of RIGB with CERES and MERRA are the strongest. Their correlation coefficients exceed 0.97 for both references, in contrast with the low values of the unadjusted data, which are 0.93 for CERES and 0.94 for MERRA. The values of the PROMICE adjustment are in-between 0.96 for both reference data sets. The RIGBadjusted insolation also better agrees with the references at GC-net and K-transect stations, with $\sim 10 \mathrm{~W} \mathrm{~m}^{-2}$ less RMSE relative to the unadjusted data, and correlation coefficients over 0.95 (Fig. 3c, d). Under all-sky conditions, the improvements in RMSE are over $20 \mathrm{~W} \mathrm{~m}^{-2}$ for both CERES and MERRA, although the absolute biases are larger (Table 2). We also notice a systematic difference of almost $50 \mathrm{~W} \mathrm{~m}^{-2}$ between CERES and MERRA. These large bias and systematic difference could be caused by the inaccurate estimates of cloud properties by the satellite instrument (i.e., CERES) and
Table 2. RMSE of AWS against the reference data sets under all-sky conditions $\left(\mathrm{W} \mathrm{m}^{-2}\right)$.

\begin{tabular}{llrcr}
\hline \multirow{2}{*}{ AWS } & Reference & Unadjusted & \multicolumn{2}{c}{ Adjustment } \\
\cline { 4 - 5 } & & & PROMICE & RIGB \\
\hline \multirow{2}{*}{ PROMICE } & CERES & 146 & $115(-21 \%)$ & $101(-31 \%)$ \\
& MERRA & 184 & $152(-17 \%)$ & $150(-18 \%)$ \\
\hline GC-Net \& & CERES & 99 & - & $77(-22 \%)$ \\
K-transect & MERRA & 154 & - & $101(-34 \%)$ \\
\hline
\end{tabular}

Numbers in the parentheses are the percentage of changes relative to the unadjusted data.

reanalysis (i.e., MERRA). Nevertheless, RIGB adjustment shows better consistencies with both references, because our adjustment is on the daily time-scale, which is shorter than that of this systematic difference.

To illustrate the agreement between the PROMICE measured and RIGB estimated tilt angles, we next compare these angles at the KPC_U station, where the station rotation is small according to the field notes taken on revisits. The 

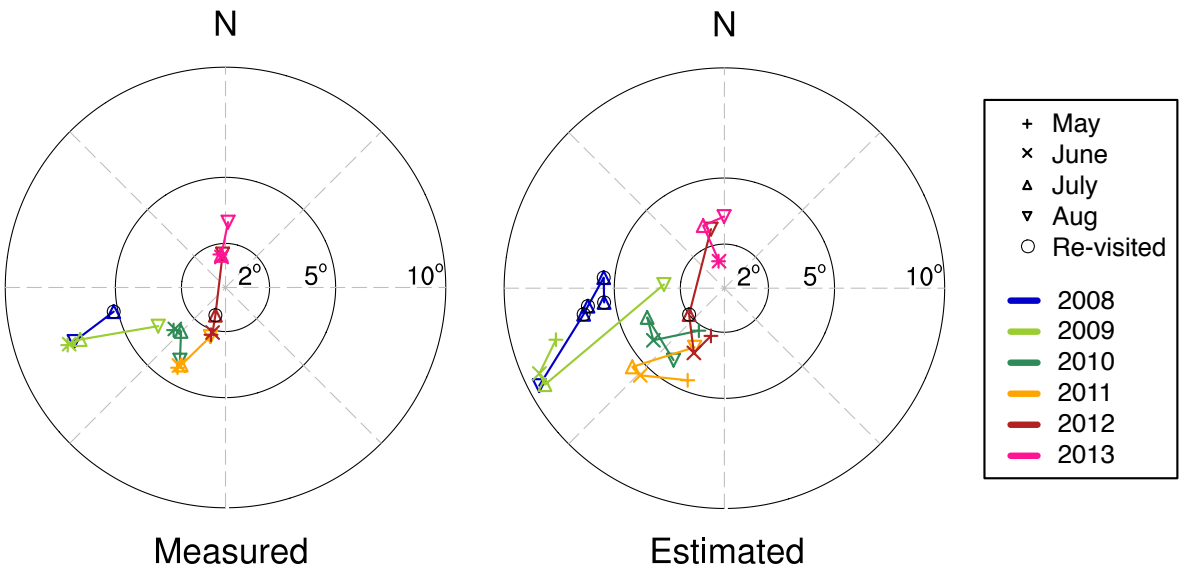

Figure 4. Measured and estimated tilt angle and tilt direction at the KPC_U station. The distance from the circle center represents the station tilt angle $(\beta)$. The direction represents the station tilt direction $\left(a_{\mathrm{W}}\right)$ with $0^{\circ}$ pointing to the South. The markers are circled in black if the station was re-visited in those months.

hourly north-south and east-west tilt angles measured by inclinometers are converted to tilt angle and tilt direction format, assuming no station rotation, and then averaged over a month. The measured and estimated tilt angle and tilt direction agree reasonably well (Fig. 4). The year-to-year relative positions are the same. The maximum absolute differences in the tilt angle and direction are 2.24 and $33.35^{\circ}$, with a root-mean-square-difference (RMSD) of 1.09 and $14.19^{\circ}$, respectively. The resulting RMSD in insolation adjustment is $6 \mathrm{~W} \mathrm{~m}^{-2}$.

The largest improvement of our tilt correction (i.e., RIGB adjustment minus unadjusted data) occurs at the South Dome, with a daily average of $32 \mathrm{~W} \mathrm{~m}^{-2}$ under all-sky conditions and $84 \mathrm{~W} \mathrm{~m}^{-2}$ under clear-sky conditions. Although the tilt angles are more variable in the ablation zone (i.e., altitude $<2000 \mathrm{~m}$ ), the absolute values are larger in the accumulation zone (i.e., altitude $>2000 \mathrm{~m}$ ), caused by the large systematic tilt at each of the southern stations. Therefore, our method improves the insolation more in the accumulation zone $\left(13 \mathrm{~W} \mathrm{~m}^{-2}\right)$ than in the ablation zone $\left(10 \mathrm{~W} \mathrm{~m}^{-2}\right.$; Table 3). The average daily improvement of all stations under all-sky conditions is $\sim 11 \mathrm{~W} \mathrm{~m}^{-2}$, which is equivalent to a snow melt in liquid of $0.24 \mathrm{~m}$ throughout the melt season, using an albedo of 0.7 for melting snow.

\section{Impact on snow surface albedo}

Snow albedo controls the absorbed solar radiation at the surface. Short-term changes in albedo can lead to snowmelt and trigger the positive snow-albedo feedbacks. Little is known about the sub-daily variabilities of albedo in the Arctic, due to a lack of high-temporal-resolution satellite observations and reliable in situ measurements. Although the polar-orbiting satellites instrument such as MODIS pass over parts of Greenland several times a day, only daily average
Table 3. Daily average improvements in insolation.

\begin{tabular}{llccc}
\hline Zone & Condition & $\begin{array}{c}\text { Unadjusted } \\
\left(\mathrm{W} \mathrm{m}^{-2}\right)\end{array}$ & $\begin{array}{c}\text { RIGB } \\
\text { adjustment } \\
\left(\mathrm{W} \mathrm{m}^{-2}\right)\end{array}$ & $\begin{array}{c}\text { Absolute } \\
\text { difference* } \\
\left(\mathrm{W} \mathrm{m}^{-2}\right)\end{array}$ \\
\hline $\begin{array}{l}\text { Accumu- } \\
\text { lation }\end{array}$ & All-Sky & 295 & 350 & $13(4 \%)$ \\
\hline \multirow{2}{*}{ Ablation } & Clear-Sky & 326 & 395 & $51(16 \%)$ \\
& All-Sky & 284 & 322 & $10(4 \%)$ \\
& Clear-Sky & 346 & 428 & $44(13 \%)$ \\
\hline
\end{tabular}

Numbers in the parentheses are the percentages of the absolute differences relative to the unadjusted insolation.

* Hourly average of absolute difference between unadjusted data and RIGB adjustment, not the difference between column 3 and 4 .

albedo is available mainly due to cloud interference. The cosine response error and the sensor tilt can introduce false diurnal fluctuations into AWS observed albedo. In climate models, the diurnal change of snow albedo is typically simulated as a function of solar zenith angle and snow grain size (van den Broeke et al., 2004; Flanner and Zender, 2006). In reality, more factors contribute to this diurnal change, including internal properties (such as particle shape and snow density) and external factors (such as solar azimuth angle and topography) (Flanner and Zender, 2006; Wang and Zender, 2011). With the tilt-corrected radiation, we find a more consistent diurnal change in surface albedo. For example, the semi-smiling curves of albedo are smoother using the adjusted data (Fig 5a, b). At stations with large tilt angles, RIGB adjusts the diurnal variability patterns from frowning to smiling (Fig. 5c, d). The average diurnal range (maximum minus minimum) of all stations declines from 0.18 to 0.12 with a 3 times smaller standard deviation.

Sometimes, the pyranometer tilts enough to jeopardize the daily average albedo, which in turn impacts climatology on long-term time scales. For example, at the UPE_L station in northwestern Greenland, the tilt angle jumped from 2.5 

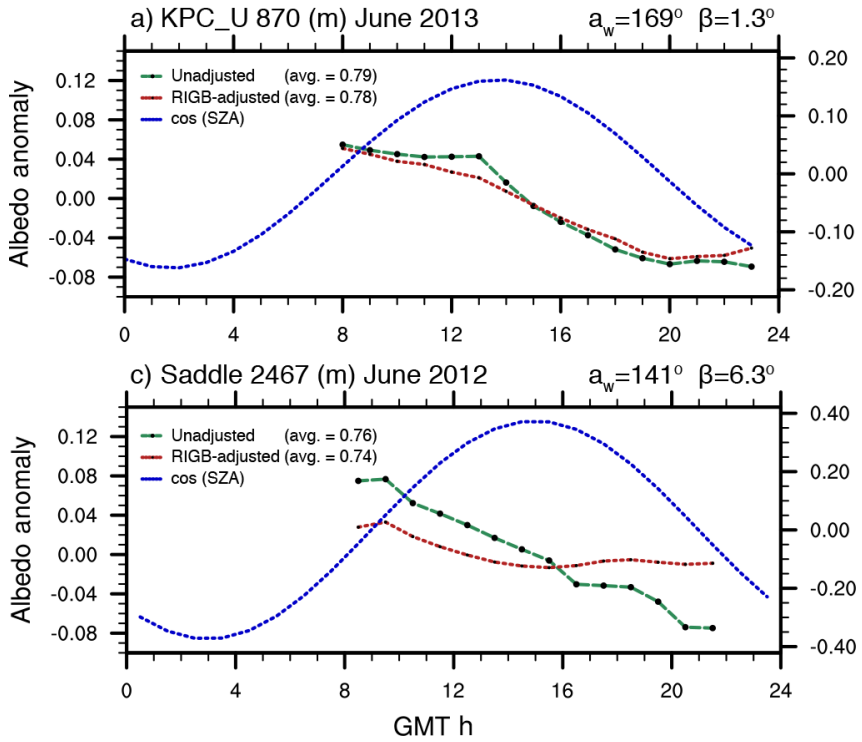

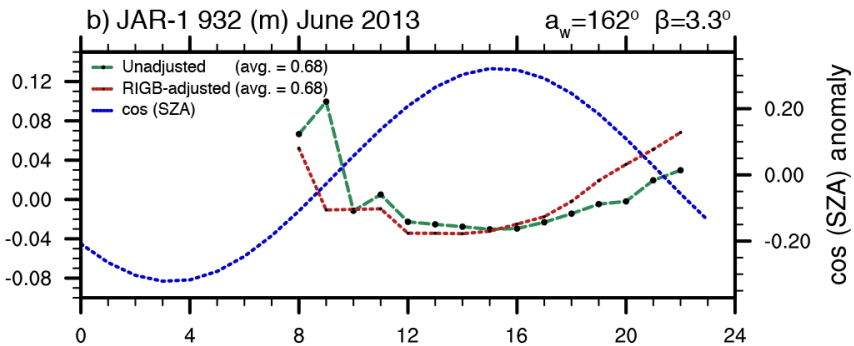

d) South Dome $2901(\mathrm{~m})$ June $2008 \quad \mathrm{a}_{\mathrm{w}}=176^{\circ} \quad \beta=15.5^{\circ}$

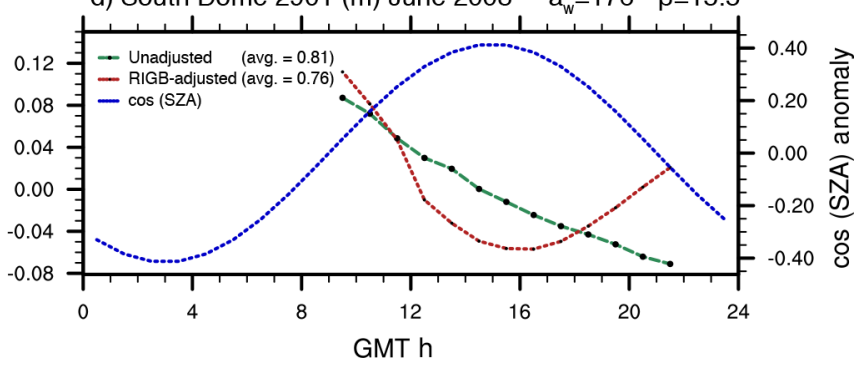

Figure 5. Diurnal variability of albedo at solar zenith angle less than $75^{\circ}$ at (a) KPC_U; (b) JAR-1; (c) Saddle; (d) South Dome. The anomaly used here is the monthly average of hourly anomalies against daily averages. cos(SZA) represents the cosine of solar zenith angle. The station altitude, tilt angle and tilt direction, and data time period are labeled on the top of each panel.

to $9.7^{\circ}$ from June to July of 2010 . Without tilt correction, data show an improbably higher albedo in July than in June (Fig. 6a), which contradicts the results from a nearby station, UPE_U (Fig. 6b), as well as the concurrent temperature trend. The high monthly average albedo in the unadjusted data in July 2010 was caused by the abnormally high values in the early mornings and late evenings, due to a shift in downwelling radiation against the upwelling. This misleading effect cannot be fully removed by either the 24-hour running average or limiting the solar zenith angle to less than $75^{\circ}$. After the tilt effect is countered, the normal climatology is restored.

Sensor tilt can also affect the inter-annual variability of albedo. In 2012, Greenland experienced the largest melt extent in the satellite era since 1979 (Nghiem et al., 2012), which is seen as an epic low albedo in both unadjusted and RIGB-adjusted data in the accumulation zone (Fig. 7a). In this area, melt only occurs during a limited period of time in the summer, and thus the tilt problem is not as serious as in the ablation zone. In spite of the large systematic tilt at the southern stations, the tilt variation is small. In the ablation zone, the unadjusted data shows the smallest albedo in 2010 instead of in 2012. Moreover, the between-station variability of the unadjusted data is almost 5 times larger than that of the RIGB-adjusted data (shown by the error bars in Fig. 7b), indicating varied tilt effects at different stations. After the tilt correction, the long-term trend and the albedo minimum are in agreement with the estimates from the NASA MOD10A data (Box, 2015).

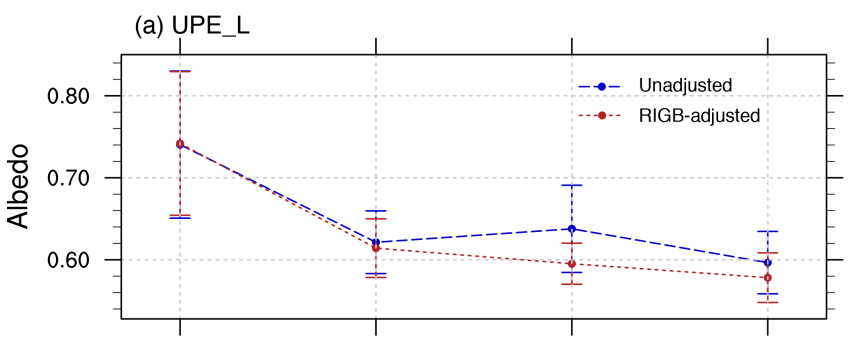

(b) UPE_U

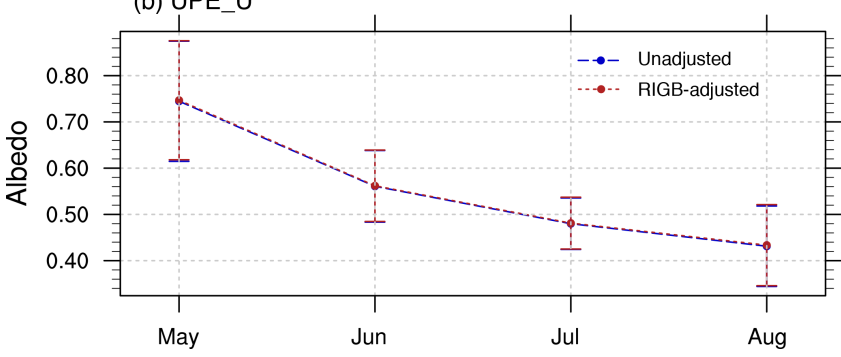

Figure 6. Monthly average albedo at (a) UPE_L and (b) UPE_U in May-August 2010 with standard deviation as error bars.

\section{Discussion}

\subsection{Station tilt}

Of all the stations examined here, only KAN_B from PROMICE is anchored into rock; all others are anchored into glacier ice. The estimated tilt angles and tilt directions reveal large temporal and spatial varieties (Fig. 8). At the GCNet stations (Fig. 8a), there is a systematic tilt direction at each station in the accumulation zone. For example, the sta- 

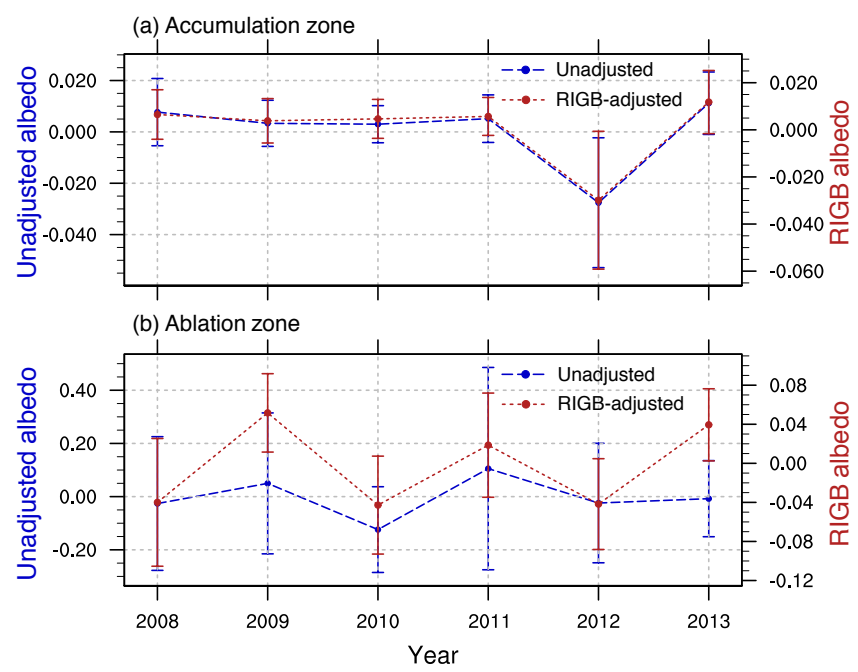

Figure 7. Annual average albedo using unadjusted data (on the left $y$ axis) and RIGB-adjusted data (on the right $y$ axis) in (a) accumulation zone; (b) ablation zone with standard deviation as error bars. The values are anomalies against the corresponding station averages.

tion at South Dome always tilts to the north, and the one at DYE-2 to the northwest. With regards to the tilt angle, both the station maximum and the temporal variability are larger in the ablation zone than in the accumulation zone, except for the South Dome station. At the PROMICE stations (Fig. 8b), there is no obvious systematic tilt direction. The tilt angles and their temporal variabilities are generally larger at the southern stations than in the northern stations. It seems that the tilt angles are less variable at GC-Net stations which use long poles as station masts than at PROMICE stations which use tripods instead. However, most GC-Net stations are in the colder accumulation zone, whereas all the PROMICE stations are in the warmer ablation zone. We also compare the temporal variability of tilt angles between the paired stations from PROMICE. The station at a higher altitude always has a smaller tilt angle standard deviation than the station at a lower altitude. In addition, the largest and most variable tilt angles are found in July when the snow melt intensity is strongest of the melt season (i.e., MayAugust). These all suggest a causal correlation between surface melt/compaction and station tilt.

Since snow melt intensity is not available at all AWS, surface albedo instead is used to compare with the tilt angle variability (Fig. 9). The significant correlation between surface albedo and station tilt variability is negative. The stations that are more northernly, at higher altitudes and with higher albedo are less affected by station tilt, whereas stations more southernly, at lower altitudes and with lower albedo are more affected. However, whether stations will tilt, and to what degree and direction also depend on environmental factors. For example, if the areas around all the anchors melt at a sim- ilar rate, the station tilt may not be as serious as one with melting that occurs only in the area around one anchor. This may explain why the correlation coefficient is relatively low $(-0.58)$. The significant correlation between near-surface atmospheric temperature and the station tilt variability is negative as well $(-0.52)$. The fact that thermometers from different projects are not set to the same height above the surface may contribute to this lower coefficient. Nevertheless, it is highly probable that the station tilt is controlled by surface melt/compaction. As the tilt angle gets larger, more environmental factors take effect.

We also found a weak negative correlation between station tilt and wind speed (i.e., the higher the wind speed, the smaller the tilt variability). However, this could be explained by the co-occurrence of high albedo and high wind speed at high-altitude stations. Moreover, no correlation is found between the systematic tilt directions of GC-Net stations in the accumulation zone and their dominating wind directions. These systematic tilt directions could be a result of the local slopes or glacier dynamics (K. Steffen, personal communication, 2015).

\subsection{Dependence on clear days}

The RIGB method requires clear days to perform the tilt estimation. With current precision, at least one clear day is needed per month. Among all the 840 station months used in this study (i.e., 35 stations, 6 years per station and 4 months per year), there are 33 station months (3.93\%) with no clear days to use. However, most of these (31 out of 33) have at least half of the AWS measurements missing. Only 2 of the 840 station months was too cloudy to have any clear days. We therefore provide no correction during that month. Another potential limit of RIGB is that it requires more clear days to accurately capture station tilt when the inter-month variability is large.

\subsection{Uncertainty in the tilt-corrected insolation}

The surface insolation simulation using CRM driven by AIRS profiles under clear-sky conditions are validated against Atmospheric Radiation Measurements (ARM) at Barrow, Alaska, USA (ARM Climate Research Facility, 1994). Since we use a constant AOD, only insolation in May is used in order to eliminate the interference of wild fires. From 2008 to 2013, the hourly average difference between the measured and simulated insolation is $5 \pm 3 \mathrm{~W} \mathrm{~m}^{-2}$, which is less than $2 \pm 1 \%$ of the daily average.

The data quality of the tilt-corrected insolation under allsky conditions also relies on the quality of cloud fraction data. Higher cloud fraction results in a higher diffuse ratio $(C)$. With more isotropic diffuse radiation, insolation is less susceptible to station tilt. Therefore, if the cloud fraction is under-estimated, the insolation will be over-corrected; vice versa. In the Arctic, the fast-changing convective clouds are 
(a)
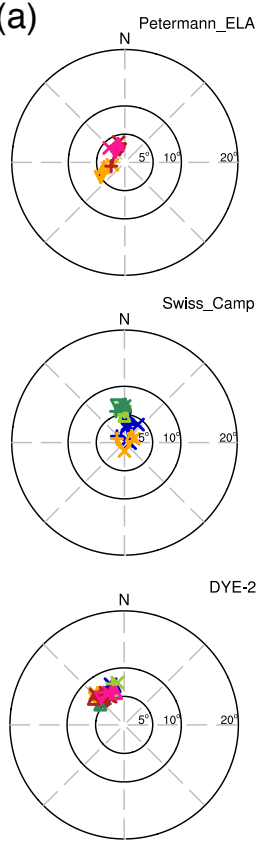

(b)
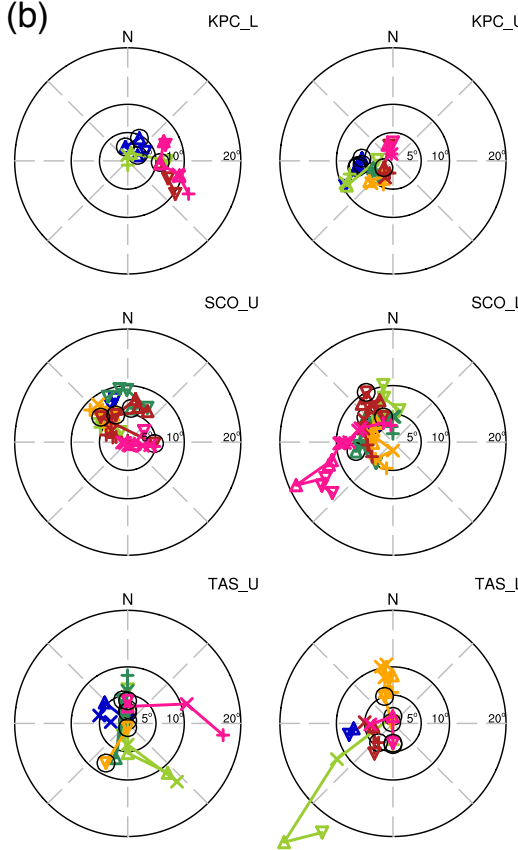

SCO_L
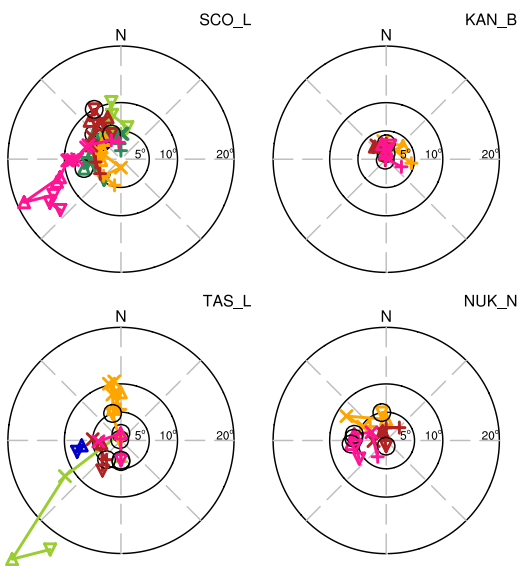

QAS
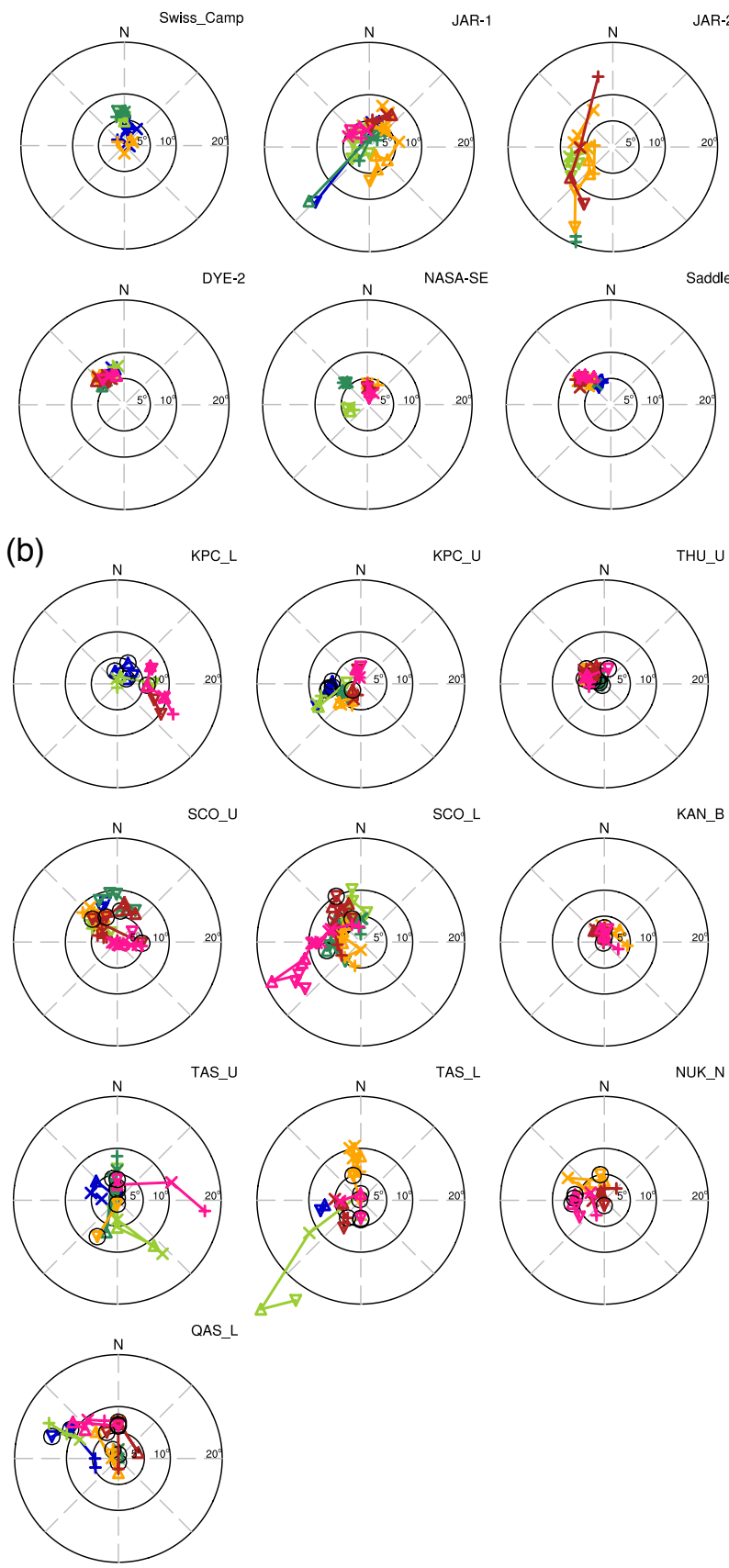
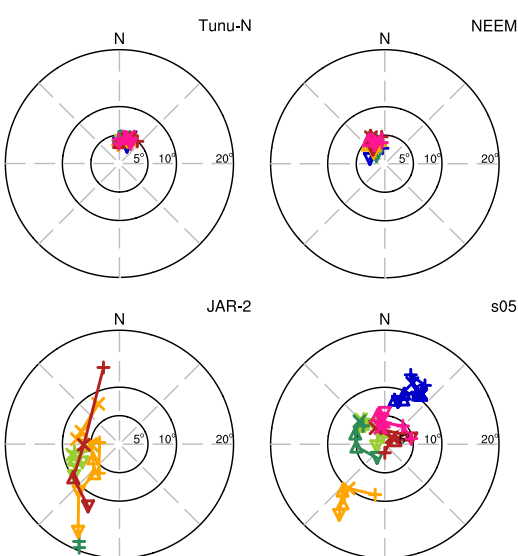

s05
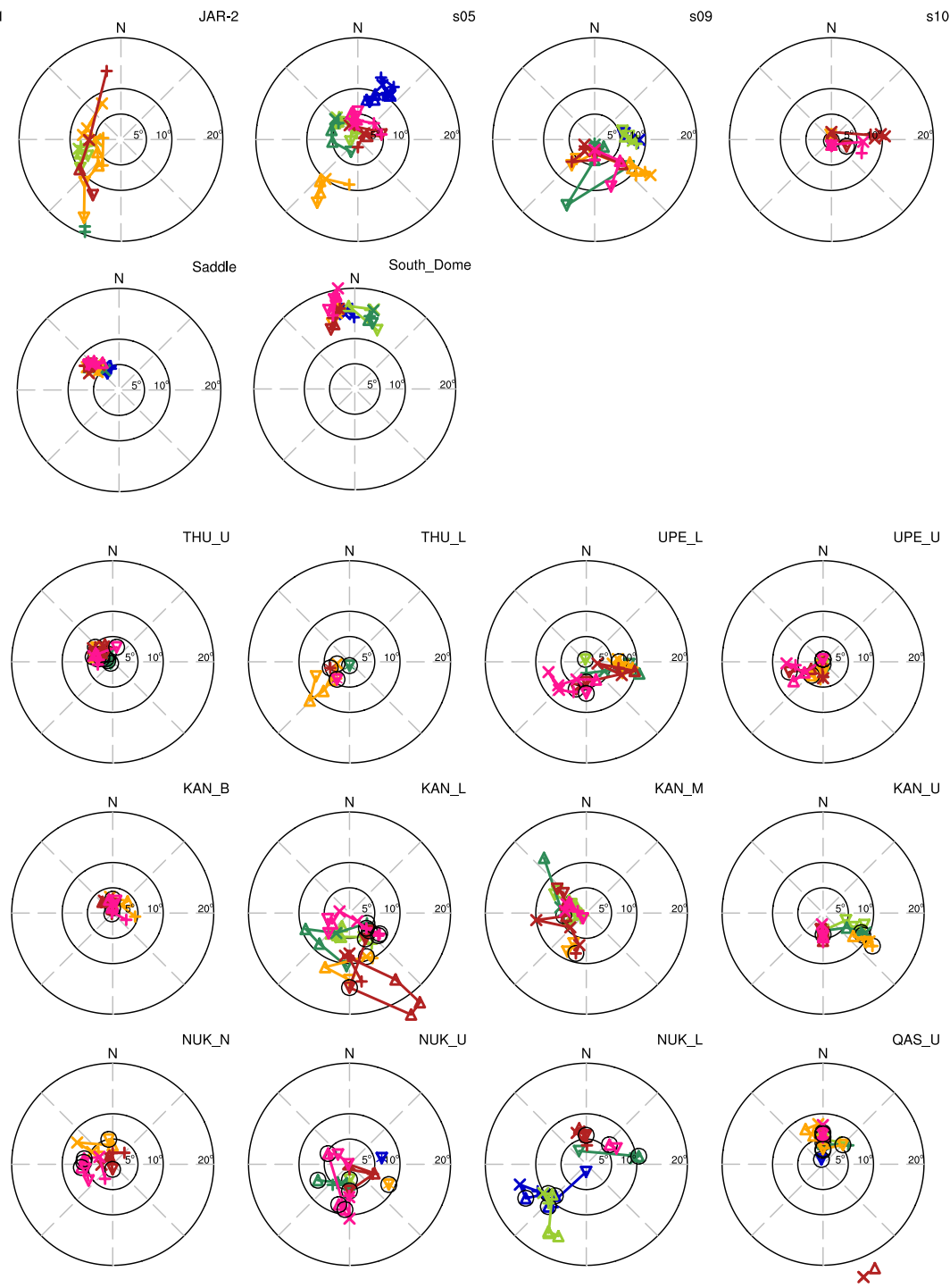

Figure 8. Station tilt angles (represented by the distance from the circle center) and tilt directions ( $0^{\circ}$ points to the South) of (a) GC-Net and K-transect; (b) PROMICE. The markers are circled in black if the stations were re-visited in those months (no re-visiting record for GC-Net is found). There might be multiple tilt angles in 1 month. The panels of stations on each sub-figure are arranged in the order of latitude, from north to south. 


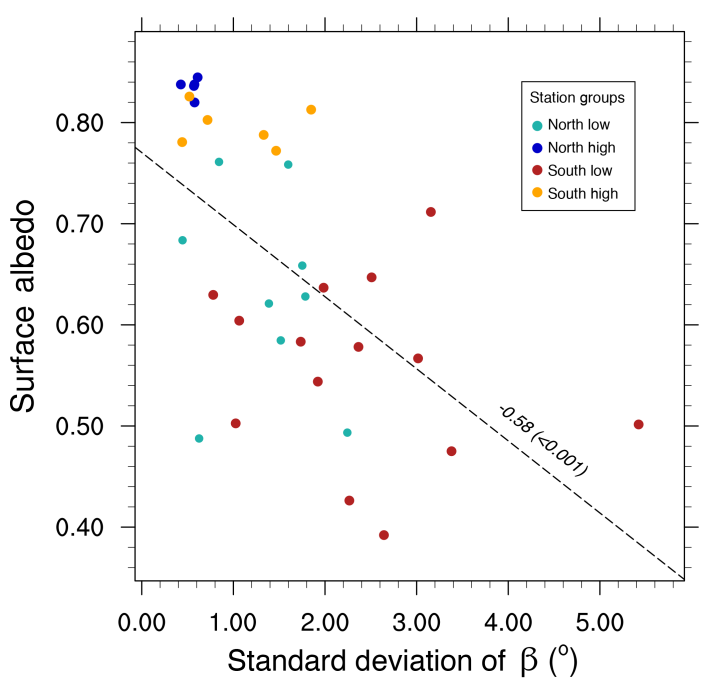

Figure 9. Correlation between surface albedo and the standard deviation of tilt angles $(\beta)$. Numbers on dashed lines are the correlation coefficients. Numbers in the parentheses are the corresponding significant levels based on a two-tailed $t$ test. The KAN_B station, which is anchored into rock is not included.

rare, so we use the 3-hourly cloud fraction from CERES. With regards to the cloud radiative properties, CERES estimates are reasonably accurate (Minnis et al., 2011). In the Arctic, the average difference between the in situ groundmeasured and CERES cloud fraction is $\sim 0.15$ (Minnis et al., 2008). The effect of cloud fraction on the insolation adjustment depends on both the tilt angles and directions (Fig. 10). The adjustment at local solar noon is largest when the station tilts to the north $\left(a_{\mathrm{w}}=180^{\circ}\right)$ or south $\left(a_{\mathrm{w}}=0^{\circ}\right)$. The maximum of daily average turns clockwise, e.g., to $a_{\mathrm{w}}=30^{\circ}$ and $a_{\mathrm{w}}=-150^{\circ}$ when the tilt angle $(\beta)$ is $10^{\circ}$. The adjustment becomes smaller when stations tilt less, or cloud fraction is close to 1 . In the worst situation when stations tilt to 30 or $210^{\circ}$ and the cloud fraction is close to 0 , the uncertainty in insolation adjustment caused by cloud uncertainty is up to $7.5 \mathrm{~W} \mathrm{~m}^{-2}$ at a tilt angle of $10^{\circ}$. In $90 \%$ of the station months we used, tilt angles are less than $10^{\circ}, 95 \%$ less than $15^{\circ}$. The average cloud fraction in the Arctic during summertime is 0.81 (Vavrus et al., 2008). Therefore, the uncertainty in insolation adjustment caused by the uncertainty in cloud fraction should be well below $10 \mathrm{~W} \mathrm{~m}^{-2}$, the magnitude of the adjustment itself. Nevertheless, a cloud fraction data set with a higher resolution would further benefit the quality of the hourly radiation measurements from AWS.

The AWS used in these three projects over Greenland Ice Sheet measure only broadband radiation. We, therefore, use a wavelength-integrated relationship between diffuse ratio $(C)$ and cloud fraction $(\mathrm{CF})$, derived from broadband radiation measurements using linear regression. Regression models using higher orders or more predictors, such as relative humidity, do not perform significantly better (Paulescu and

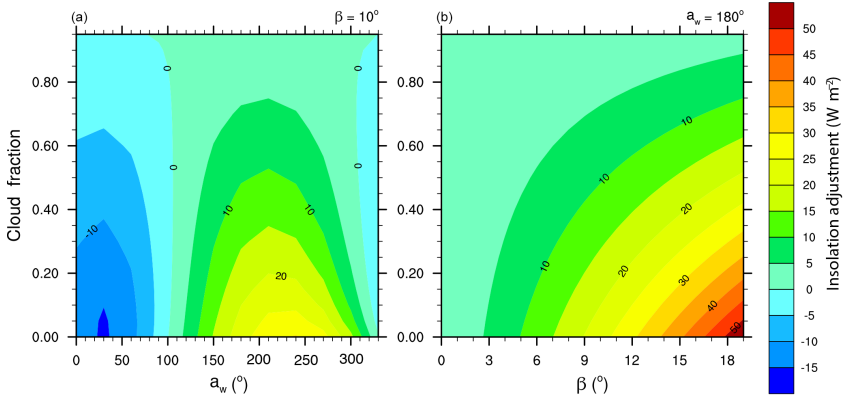

Figure 10. The effect of cloud fraction on daily average tilt correction of insolation changing with (a) tilt direction $\left(a_{\mathrm{W}}\right)$ and (b) tilt angle $(\beta)$.

Blaga, 2016). Also, there is no significant difference in the calculation of radiation on tilted surface by using diffuse radiation estimated from a diffuse fraction correlation or retrieved from observations (Reindl et al., 1990). Although tiltinduced errors are independent of wavelength for direct radiation, they vary with wavelength for diffuse radiation (Bogren et al., 2015). The diffuse/direct ratio $(C)$ also increases with shorter wavelengths (Hudson et al., 2006; Bogren et al., 2015). The equations in Sect. 3 could be instead written as function of wavelength with diffuse ratio, $C(\lambda)$, and radiation fluxes, $I(\lambda)$. Therefore, if narrow-band measurements of shortwave radiation and the corresponding diffuse ratios are available, RIGB can be applied to correct spectral tiltinduced errors.

\section{Conclusions}

In this study, we identify and correct the SW tilt bias using tilt angles and directions estimated by comparing CRM simulated insolation with AWS observed insolation under clearsky conditions. Station tilt causes considerable bias in insolation. On fewer than $40 \%$ of clear days, the unadjusted insolation peaks at the correct solar noon time $( \pm 0.5 \mathrm{~h})$. The largest bias exceeds $3 \mathrm{~h}$. The unadjusted insolation RMSE against CERES and MERRA at all stations are as large as $\sim 70 \mathrm{~W} \mathrm{~m}^{-2}$ under clear-sky conditions, with a correlation coefficient of $\sim 0.90$. Using the estimated tilt angles and tilt directions, which are in a good agreement with the measured tilt angles, RIGB adjustment reduces the RMSE by $16 \mathrm{~W} \mathrm{~m}^{-2}$, and enhances the correlation coefficients to above 0.95 . The overall improvement relative to the unadjusted data under all-sky conditions is $11 \mathrm{~W} \mathrm{~m}^{-2}$, which is enough to melt $0.24 \mathrm{~m}$ snow water equivalent using an albedo of 0.7 . With this tilt-corrected SW data, we found a consistent semismiling diurnal cycle of albedo in Greenland. The derived seasonal and inter-annual variabilities of albedo agree better with satellite observations and temperature changes. This RIGB tilt-correction method relies only on the iterative application of solar geometric principles, that requires no addi- 
tional instrumentation. Therefore, it can retrospectively solve the tilt problems in SW measurement, and provides multiyear consistent SW for the analysis of surface energy budgets and melt as well as validation of satellite observations and model simulations on Greenland Ice Sheet and in other snow-covered areas. 
Appendix A: Nomenclature (Table A1)

Table A1. Variables used in Sect. 3.

\begin{tabular}{ll}
\hline$I_{\mathrm{h}}$ & Shortwave radiation on a horizontal surface, $\mathrm{W} \mathrm{m}^{-2}$ \\
$I_{\mathrm{t}}$ & Shortwave radiation on a tilted surface, $\mathrm{W} \mathrm{m}^{-2}$ \\
$I_{\mathrm{b}, \mathrm{h} / \mathrm{t}}$ & Beam radiation on a horizontal/tilted surface, $\mathrm{W} \mathrm{m}^{-2}$ \\
$I_{\mathrm{d}, \mathrm{h} / \mathrm{t}}$ & Diffuse radiation on a horizontal/tilted surface, $\mathrm{W} \mathrm{m}^{-2}$ \\
$I_{\mathrm{r}, \mathrm{t}}$ & Reflected radiation from a nearby horizontal surface on a tilted surface, $\mathrm{W} \mathrm{m}^{-2}$ \\
$\beta$ & Tilt angle, radians \\
$a_{\mathrm{W}}$ & Tilt direction, radians \\
$z$ & Solar zenith angle observed from a horizontal surface, radians \\
$i$ & Solar zenith angle observed from a tilted surface, radians \\
$a_{\mathrm{S}}$ & Solar azimuth angle, radians \\
$C$ & Diffuse ratio \\
$\rho$ & Surface albedo approximation \\
$\mathrm{CF}$ & Cloud fraction \\
\hline
\end{tabular}


Acknowledgements. Wenshan Wang thanks Carolyn McClaskey, Andreas Peter Ahlstrøm, Konrad Steffen, Marie Dumont and the anonymous reviewer for their constructive feedbacks. The authors acknowledge the GC-Net team for providing and helping to interpret AWS measurements. CERES cloud and radiation data were obtained from the NASA Langley Research Center Atmospheric Science Data Center; MERRA radiation data were obtained from the Global Modeling and Assimilation Office and the Goddard Earth Sciences Data and Information Services Center. This work was funded by NASA Grants NNX12AF48A and NNX14AH55A.

Edited by: V. Radic

\section{References}

AIRS Science Team/Joao Texeira: Aqua AIRS Level 2 Support Retrieval (AIRS+AMSU), version 006, NASA Goddard Earth Science Data and Information Services Center (GES DISC), Greenbelt, MD, USA, doi:10.5067/AQUA/AIRS/DATA207, 2013.

Andersen, M., Stenseng, L., Skourup, H., Colgan, W., Khan, S., Kristensen, S., Andersen, S., Box, J., Ahlstrøm, A., Fettweis, X., and Forsberg, R.: Basin-scale partitioning of Greenland ice sheet mass balance components (2007-2011), Earth Planet. Sc. Lett., 409, 89-95, doi:10.1016/j.eps1.2014.10.015, 2015.

ARM (Atmospheric Radiation Measurement) Climate Research Facility: Data Quality Assessment for ARM Radiation Data (QCRAD1LONG). 2008-05-01 to 2013-05-31, $71.323 \mathrm{~N}$ 156.609 W: North Slope Alaska (NSA) Central Facility, Barrow AK (C1), Oak Ridge, Tennessee, USA, compiled by: Shi, Y. and Riihimaki, L., doi:10.5439/1027372, 1994.

Bais, A. F., Kazadzis, S., Balis, D., Zerefos, C. S., and Blumthaler, M.: Correcting global solar ultraviolet spectra recorded by a brewer spectroradiometer for its angular response error, Appl. Optics, 37, 6339-6344, doi:10.1364/AO.37.006339, 1998.

Biggs, W. W.: Principles of Radiation Measurement, in: Excerpted from: Advanced Agricultural Instrumentation, Proceedings from the NATO Advanced Study Institute on "Advanced Agricultural Instrumentation”, edited by: Gensler, W., Martinus Nijhof, Dordrecht, The Netherlands, 2 Edn., 1-17, doi:10.1016/B978-0-12374271-1.00071-X, 2015.

Bogren, W. S., Burkhart, J. F., and Kylling, A.: Tilt error in cryospheric surface radiation measurements at high latitudes: a model study, The Cryosphere Discuss., 9, 4355-4376, doi:10.5194/tcd-9-4355-2015, 2015.

Box, J. E.: Greenland melt season kicks off slowly in 2015; the new abnormal, http://www.meltfactor.org/blog/ greenland-melt-season-kicks-off-slowly-in-2015/ (last access: 1 July 2015), 2015.

Box, J. E., Fettweis, X., Stroeve, J. C., Tedesco, M., Hall, D. K., and Steffen, K.: Greenland ice sheet albedo feedback: thermodynamics and atmospheric drivers, The Cryosphere, 6, 821-839, doi:10.5194/tc-6-821-2012, 2012.

CERES Science Team: CERES SYN1deg-3Hour, Ed3A, NASA Atmospheric Science Data Center (ASDC), Hampton, VA, USA, doi:10.5067/Terra+Aqua/CERES/SYN1deg3HOUR_L3.003A, 2015.

Enderlin, E. M., Howat, I. M., Jeong, S., Noh, M.-J., van Angelen, J. H., and van den Broeke, M. R.: An improved mass budget for the Greenland ice sheet, Geophys. Res. Lett., 41, 866-872, doi:10.1002/2013GL059010, 2014.

Fettweis, X.: Reconstruction of the 1979-2006 Greenland ice sheet surface mass balance using the regional climate model MAR, The Cryosphere, 1, 21-40, doi:10.5194/tc-1-21-2007, 2007.

Flanner, M. G. and Zender, C. S.: Linking snowpack microphysics and albedo evolution, J. Geophys. Res., 111, D12208, doi:10.1029/2005JD006834, 2006.

Goswami, D., Kreith, F., and Kreider, J.: Radiation on tilted surface, in: Principles of Solar Engineering, 2nd Edn., Taylor \& Francis, Philadelphia, PA, USA, 2000.

Grenfell, T. C., Warren, S. G., and Mullen, P. C.: Reflection of solar radiation by the Antarctic snow surface at ultraviolet, visible, and near-infrared wavelengths, J. Geophys. Res., 99, 18669, doi:10.1029/94JD01484, 1994.

Harrison, R. G., Chalmers, N., and Hogan, R. J.: Retrospective cloud determinations from surface solar radiation measurements, Atmos. Res., 90, 54-62, doi:10.1016/j.atmosres.2008.04.001, 2008.

Hudson, S. R., Warren, S. G., Brandt, R. E., Grenfell, T. C., and Six, D.: Spectral bidirectional reflectance of Antarctic snow: Measurements and parameterization, J. Geophys. Res., 111, D18106, doi:10.1029/2006JD007290, 2006.

Kipp \& Zonen: Instruction manual for Kipp \& Zonen CM3, Tech. rep., Kipp \& Zonen B.V., Delft, Holland, 36 pp., 2004.

Kuipers Munneke, P., Reijmer, C. H., and van den Broeke, M. R.: Assessing the retrieval of cloud properties from radiation measurements over snow and ice, Int. J. Climatol., 31, 756-769, doi:10.1002/joc.2114, 2011.

Minnis, P., Trepte, Q. Z., Sun-Mack, S., Chen, Y., Doelling, D. R., Young, D. F., Spangenberg, D. A., Miller, W. F., Wielicki, B. A., Brown, R. R., Gibson, S. C., and Geier, E. B.: Cloud detection in nonpolar regions for CERES using TRMM VIRS and Terra and Aqua MODIS data, IEEE T. Geosci. Remote, 46, 3857-3884, doi:10.1109/TGRS.2008.2001351, 2008.

Minnis, P., Sun-Mack, S., Chen, Y., Khaiyer, M. M., Yi, Y., Ayers, J. K., Brown, R. R., Dong, X., Gibson, S. C., Heck, P. W., Lin, B., Nordeen, M. L., Nguyen, L., Palikonda, R., Smith, W. L., Spangenberg, D. A., Trepte, Q. Z., and Xi, B.: CERES edition2 cloud property retrievals using TRMM VIRS and Terra and Aqua MODIS data - Part II: Examples of average results and comparisons with other data, IEEE T. Geosci. Remote, 49, 44014430, doi:10.1109/TGRS.2011.2144602, 2011.

Nghiem, S. V., Hall, D. K., Mote, T. L., Tedesco, M., Albert, M. R., Keegan, K., Shuman, C. A., DiGirolamo, N. E., and Neumann, G.: The extreme melt across the Greenland ice sheet in 2012, Geophys. Res. Lett., 39, L20502, doi:10.1029/2012GL053611, 2012.

Paulescu, E. and Blaga, R.: Regression models for hourly diffuse solar radiation, Sol. Energy, 125, 111-124, doi:10.1016/j.solener.2015.11.044, 2016.

Pithan, F. and Mauritsen, T.: Arctic amplification dominated by temperature feedbacks in contemporary climate models, Nat. Geosci., 7, 181-184, doi:10.1038/ngeo2071, 2014.

Reda, I. and Andreas, A.: Solar position algorithm for solar radiation applications, Sol. Energy, 76, 577-589, doi:10.1016/j.solener.2003.12.003, 2004. 
Reindl, D., Beckman, W., and Duffie, J.: Evaluation of hourly tilted surface radiation models, Sol. Energy, 45, 9-17, doi:10.1016/0038-092X(90)90061-G, 1990.

Rienecker, M. M., Suarez, M. J., Gelaro, R., Todling, R., Bacmeister, J., Liu, E., Bosilovich, M. G., Schubert, S. D., Takacs, L., Kim, G.-K., Bloom, S., Chen, J., Collins, D., Conaty, A., da Silva, A., Gu, W., Joiner, J., Koster, R. D., Lucchesi, R., Molod, A., Owens, T., Pawson, S., Pegion, P., Redder, C. R., Reichle, R., Robertson, F. R., Ruddick, A. G., Sienkiewicz, M., and Woollen, J.: MERRA: NASA's Modern-Era Retrospective Analysis for Research and Applications, J. Climate, 24, 3624-3648, doi:10.1175/JCLI-D-11-00015.1, 2011.

Schaaf, C. B., Wang, Z., and Strahler, A. H.: Commentary on Wang and Zender-MODIS snow albedo bias at high solar zenith angles relative to theory and to in situ observations in Greenland, Remote Sens. Environ., 115, 1296-1300, doi:10.1016/j.rse.2011.01.002, 2011.

Steffen, C., Box, J., and Abdalati, W.: Greenland Climate Network: GC-Net, US Army Cold Regions Reattach and Engineering (CRREL), CRREL Special Report, 98-103, 1996.

Stroeve, J., Box, J. E., Gao, F., Liang, S., Nolin, A., and Schaaf, C.: Accuracy assessment of the MODIS 16-day albedo product for snow: comparisons with Greenland in situ measurements, Remote Sens. Environ., 94, 46-60, doi:10.1016/j.rse.2004.09.001, 2005.

Stroeve, J., Box, J. E., Wang, Z., Schaaf, C., and Barrett, A.: Re-evaluation of MODIS MCD43 Greenland albedo accuracy and trends, Remote Sens. Environ., 138, 199-214, doi:10.1016/j.rse.2013.07.023, 2013.

Stroeve, J. C., Box, J. E., Fowler, C., Haran, T., and Key, J.: Intercomparison between in situ and AVHRR polar pathfinder-derived surface albedo over Greenland, Remote Sens. Environ., 75, 360374, doi:10.1016/S0034-4257(00)00179-6, 2001.

Susskind, J., Barnet, C., and Blaisdell, J.: Retrieval of atmospheric and surface parameters from AIRS/AMSU/HSB data in the presence of clouds, IEEE T. Geosci. Remote, 41, 390-409, doi:10.1109/TGRS.2002.808236, 2003.

Tedesco, M., Fettweis, X., Mote, T., Wahr, J., Alexander, P., Box, J. E., and Wouters, B.: Evidence and analysis of 2012 Greenland records from spaceborne observations, a regional climate model and reanalysis data, The Cryosphere, 7, 615-630, doi:10.5194/tc7-615-2013, 2013.

van As, D.: Warming, glacier melt and surface energy budget from weather station observations in the Melville Bay region of northwest Greenland, J. Glaciology, 57, 208-220, doi:10.3189/002214311796405898, 2011. van As, D. and Fausto, R. S.: Programme for Monitoring of the Greenland Ice Sheet (PROMICE): first temperature and ablation records, Geol. Surv. Den. Greenl., 23, 73-76, 2011.

van As, D., Andersen, M. L., Petersen, D., Fettweis, X., Van Angelen, J. H., Lenaerts, J. T., Van Den Broeke, M. R., Lea, J. M., Bøggild, C. E., Ahlstrøm, A. P., and Steffen, K.: Increasing meltwater discharge from the Nuuk region of the Greenland ice sheet and implications for mass balance (1960-2012), J. Glaciology, 60, 314-322, doi:10.3189/2014JoG13J065, 2014.

van den Broeke, M., van As, D., Reijmer, C., and van de Wal, R.: Assessing and Improving the Quality of Unattended Radiation Observations in Antarctica, J. Atmos. Ocean. Techn., 21, 1417-1431, doi:10.1175/15200426(2004)021<1417:AAITQO>2.0.CO;2, 2004.

van den Broeke, M., Bamber, J., Ettema, J., Rignot, E., Schrama, E., van de Berg, W. J., van Meijgaard, E., Velicogna, I., and Wouters, B.: Partitioning recent Greenland mass loss, Science (New York, N.Y.), 326, 984-6, doi:10.1126/science.1178176, 2009.

van den Broeke, M. R., Smeets, C. J. P. P., and van de Wal, R. S. W.: The seasonal cycle and interannual variability of surface energy balance and melt in the ablation zone of the west Greenland ice sheet, The Cryosphere, 5, 377-390, doi:10.5194/tc-5-377-2011, 2011.

Vavrus, S., Waliser, D., Schweiger, A., and Francis, J.: Simulations of 20th and 21st century Arctic cloud amount in the global climate models assessed in the IPCC AR4, Clim. Dynam., 33, 1099-1115, doi:10.1007/s00382-008-0475-6, 2008.

Velicogna, I. and Wahr, J.: Time-variable gravity observations of ice sheet mass balance: Precision and limitations of the GRACE satellite data, Geophys. Res. Lett., 40, 3055-3063, doi:10.1002/grl.50527, 2013.

Wang, X. and Zender, C. S.: Constraining MODIS snow albedo at large solar zenith angles: Implications for the surface energy budget in Greenland, J. Geophys. Res., 115, F04015, doi:10.1029/2009JF001436, 2010a.

Wang, X. and Zender, C. S.: MODIS snow albedo bias at high solar zenith angles relative to theory and to in situ observations in Greenland, Remote Sens. Environ., 114, 563-575, doi:10.1016/j.rse.2009.10.014, 2010b.

Wang, X. and Zender, C. S.: Arctic and Antarctic diurnal and seasonal variations of snow albedo from multiyear Baseline Surface Radiation Network measurements, J. Geophys. Res., 116, F03008, doi:10.1029/2010JF001864, 2011.

Zender, C. S.: Global climatology of abundance and solar absorption of oxygen collision complexes, J. Geophys. Res., 104, 24471, doi:10.1029/1999JD900797, 1999. 